\title{
ASSIMILATING GEOSPATIAL METAMODEL AND INVENTORY MAPPING FOR NON-STRUCTURAL MITIGATION OF LANDSLIDE
}

\author{
N. S. Nasir ${ }^{1}$, M. F. Abdul Khanan ${ }^{1 *}$, S. H. Othman ${ }^{2}$, M. Z. Abdul Rahman ${ }^{1}$, K. A. Razak ${ }^{3}$, M. R. Mohd Salleh ${ }^{1}$, \\ H. A. Umar ${ }^{4}$, A. N. Abdul Razak ${ }^{5}$ \\ ${ }^{1}$ Faculty of Built Environment and Survey, Universiti Teknologi Malaysia, Johor Bahru, Malaysia - mdfaisal@utm.my \\ ${ }^{2}$ Department of Computer Science, Faculty of Computing, Universiti Teknologi Malaysia, Johor Bahru, Malaysia \\ ${ }^{3}$ Razak School of Technology and Informatics, Universiti Teknologi Malaysia, Kuala Lumpur, Malaysia \\ ${ }^{4}$ Department of Environmental Sciences, Federal University Dutse, P.M.B. 7156, Dutse, Nigeria \\ ${ }^{5}$ Faculty of Social Sciences and Humanities, Universiti Teknologi Malaysia, Johor Bahru, Malaysia
}

KEY WORDS: Metamodel, geospatial metamodel, disaster management, landslide, landslide inventory mapping

\begin{abstract}
:
In Malaysia, issues related to disaster management are always given attention in society and by the responsible parties. However, in general, citizen do not think of the consequential impact of disaster due to less of knowledge regarding the early phase in disaster management. Therefore, citizen in those areas will be more vulnerable to landslide as the citizen face difficulties in identifying specific areas with the tendency of landslides. This paper presents a geospatial metamodel approach for non-structural mitigation of landslide using data from airborne LiDAR and aerial photograph. Disaster management metamodel with geospatial element combines activity for managing disaster along with geospatial database that makes it handy for appreciating the metamodel. On the other hand, the digital terrain model (DTM) from LiDAR and aerial photograph is required to produce landslide inventory mapping. The case study area is located in Kundasang, Sabah, where landslides occur frequently. In order to get better visual in identifying landslides in the study area, three types of data are required to carry out image interpretation. The three types of data are hillshade, topographic openness and colour composite. The result of the landslide inventory map shows that there are five types of landslide, which is debris flow, debris fall, mud flow, deep-seated landslide and shallow landslide. Finally, the result of landslide inventory map will be integrated into the developed metamodel for presentation to the users. This landslide inventory map is used as a non-structural mitigation step in one of disaster management phases that is suitable to prepare and use in mitigating the landslide hazard impact.
\end{abstract}

\section{INTRODUCTION}

Landslide is the mass movement of soil, rock or debris material forming a slope toward the external and lower part of the slope along a defined sliding surface (Agliardi, 2012). Landslides can occur unexpectedly and there are several factors that can cause landslides such as rain, earthquakes and effects of human activity.

Other factors that can cause landslide are the effects of human activity and such as development activities carried out on the slopes and the uncontrolled cutting down of forest trees. According to Danish K. et. al. (2017), landslide that occurred in Highland Tower. Highland Tower, which is located in Taman Hillview, Hulu Klang, Selangor and built in December 1993, has received attention as the worst landslide ever to occur in Malaysia. Due to the impact of the landslide, many residents in the area lost their homes, property and also life. Therefore, to reduce the damage caused by the disaster, disaster management is used to plan the process before, during and after disaster.

According to Chatterjee (2016), disaster management includes all aspects of planning for and responding to disaster and emergencies, including both pre and post event activities. To control disasters such as landslides, four phases of disaster management procedures have to be adapted. These four phases of disaster management are mitigation, preparedness, rescue and recovery. Each phase is different in terms of operations and actions to be taken, however only the mitigation phase is considered for this paper.

The first phase of disaster management is mitigation. Mitigation is the stage before the disaster. In this phase, the activities that can be carried out are public awareness related to disasters, information related to the disaster, building codes and zoning. In this phase, public awareness is very important to open the eyes of all citizens to realize that the impact of the disaster is very bad if loss of life occurs.

Although this paper only concerns the mitigation phase, the entire four phases need to be done to ensure that disaster management goals are achieved. According to Chatterjee (2016), the goals of disaster management are to minimize losses from the disaster, to create effective recovery and pro activate plans to mitigate various risks. Therefore, various ways can be used to achieve disaster management goals, one of which is to use metamodel.

Metamodel is a model about a model. According to Visconti and Cook (2002), metamodel is a further abstraction of a model for constructing models for single-focus process areas. Metamodel is used as a language to describe disaster management and create a decision support system to unify, facilitate and speed up the process of managing disaster. Metamodel is the analysis, construction and development of the models for modeling a predefined class of problems (Berci et al., 2009). Disaster management can be implemented efficiently if metamodel is used for managing disaster.

Metamodel can be used in the disaster management process as it is one of the most effective ways to get the perfect solution and it can support all stages of disaster management. All the activities specified in each phase will be shown in the form of a metamodel system which can be translated into the form of software engineering and this allows disaster management to become an efficient management. According to Othman and 
Beydoun (2010), metamodel can also serve as an effective tool to determine the completeness of any disaster management solution.

The 2015 landslide that occurred at Kundasang, Sabah has caused a lot of damage to property and loss of life (The Star Online, 2015). Therefore, a disaster management metamodel needs to be developed as one of the non-structural mitigation aspects when it comes to managing the disaster such as this. Metamodel is a language to show the model. Hence, metamodel is an important tool to ensure that disaster management can be controlled and managed effectively. Disaster Management metamodel can be used by many agencies such as National Disaster Management Agency (NADMA) and local authorities.

This study aims to produce metamodel and map for mitigation phase in disaster management by applying geospatial aspects. These are the objectives of this study to ensure that the aim of this study can be achieved:

i. To review the current non-structural mitigation in landslide inventory map.

ii. To develop a geospatial integrated metamodel for mitigation phase in disaster management.

iii. To show the current landslide in Kundasang, Sabah for mitigation purpose.

\section{METHODOLOGY}

The overall methodology can be divided into five stages including data collection, data pre-processing, generation of landslide inventory map, generation of metamodel and generation of geospatial metamodel. Data collection phases will have primary and secondary data, which are required to generate landslide inventory and disaster management metamodel before it will be combined to produce geospatial metamodel (GeoMet). In order to achieve the objectives, this section will discuss the data sources, materials used and concepts of this study. Figure 1 shows the flow of methodology for geospatial metamodel and landslide inventory map.

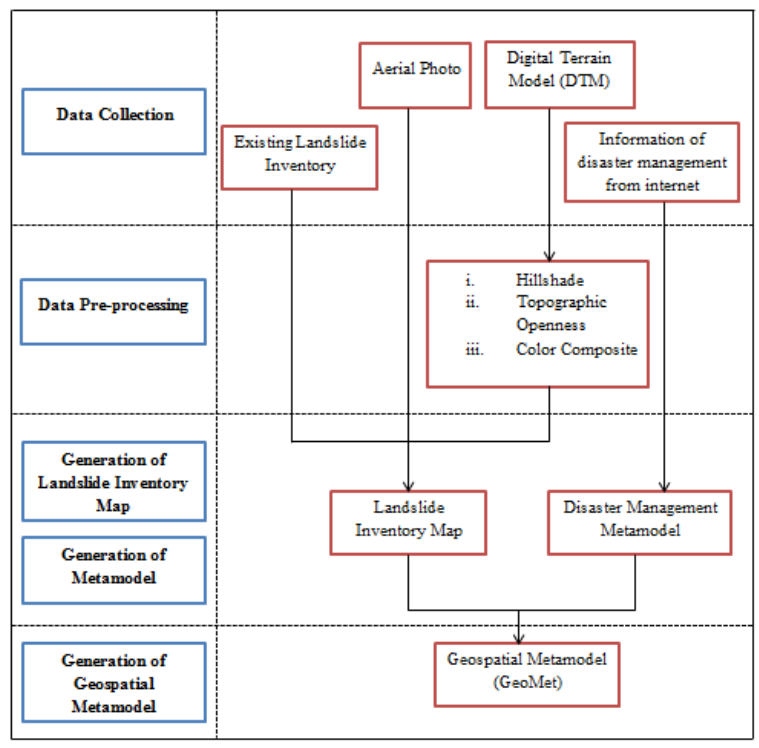

Figure 1. Methodological Flow

\subsection{Study Area}

The study area for this study is Kundasang, Sabah. Kundasang is located on the west coast of Sabah, Malaysia. Figure 2 shows the map of Sabah with the Kundasang area highlighted. Kundasang is a town in the district of Ranau, in Sabah, Malaysia and Kundasang is the closest town to Mount Kinabalu.

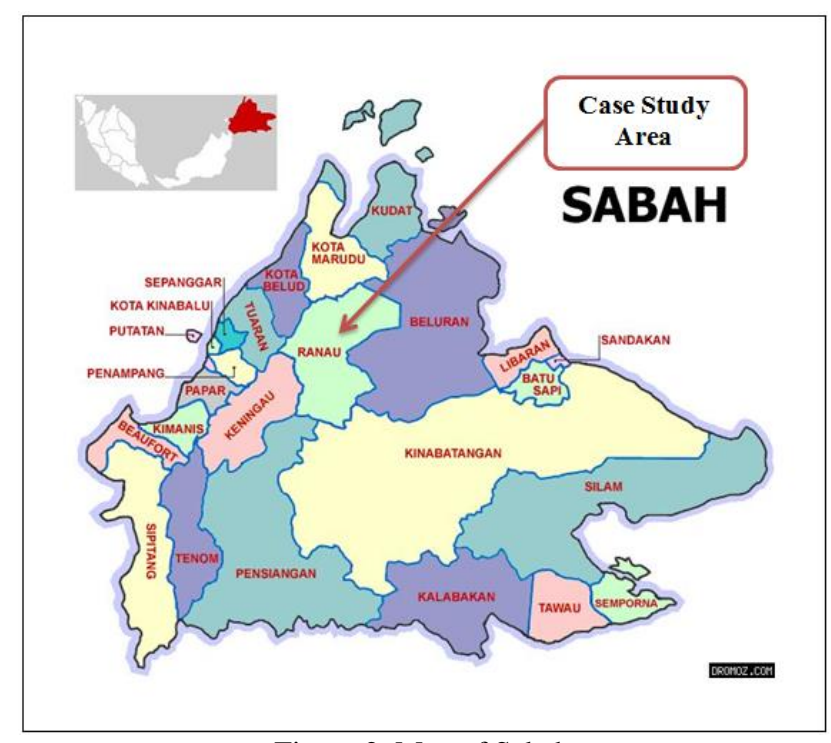

Figure 2. Map of Sabah

Figure 3 shows the spcific location of the study area in Kundasang, Sabah.

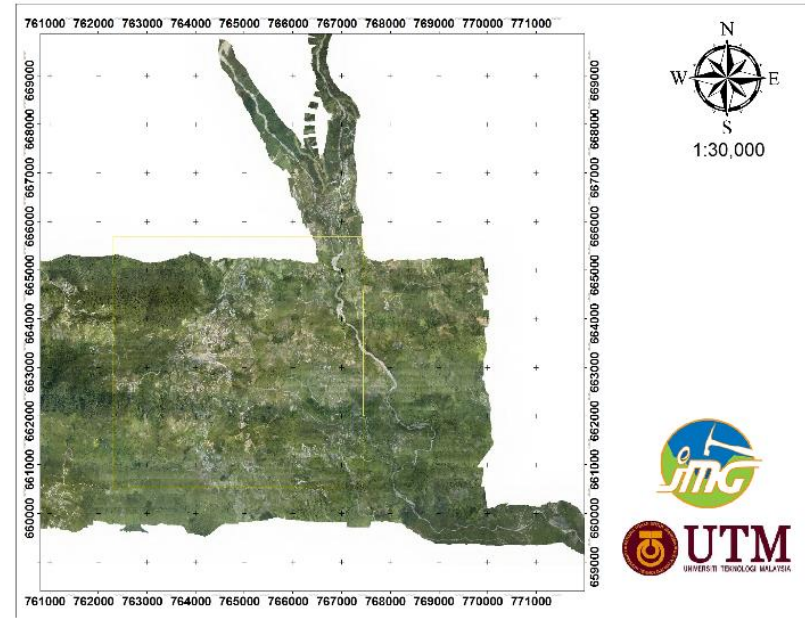

Figure 3. Location of Study Area

According to Petley (2015), landslides have been generated by the earthquake that occurred in Sabah in 5th June 2015 that released large volumes of sediment. Heavy rain in Sabah has caused the sediment to enter the river system and form mudflows and sediment-rich flash flood. As a result of the impact of the earthquake, 18 citizen died in rock falls on Mount Kinabalu.

Kundasang, Sabah became the place to do this study because many landslides occur in Sabah due to earthquakes. On 21st October 2017, landslide occurred on the foothill of Mount Kinabalu after the tragic earthquake which took place two years ago in 2015 (New Straits Time, 2017).

In addition, the landslide that occurred at Kundasang caused by heavy rain followed by a powerful 5.2 magnitude earthquake, forced the evacuation of 700 citizen from 100 houses to the evacuation centers that were provided (The Star Online, 2015). 


\subsection{Data Colletion}

Data collection will take place in order to design disaster management metamodel and landslide inventory mapping for Kundasang, Sabah. There are two types of data: (1) primary data and (2) secondary data. Primary data is raw data obtained from fieldwork such as self-picked data, while secondary data is data obtained from agencies that provide the data. Table 1 shows the data needed to produce metamodel and landslide inventory mapping.

\begin{tabular}{|c|c|c|}
\hline \multicolumn{3}{|c|}{ Data } \\
\hline \multicolumn{2}{|c|}{$\begin{array}{c}\text { Disaster Management } \\
\text { Metamodel }\end{array}$} & $\begin{array}{c}\text { Landslide Inventory } \\
\text { Mapping }\end{array}$ \\
\hline & $\begin{array}{l}\text { PBRC project } \\
\text { report }\end{array}$ & $\begin{array}{ll}\text { i. } & \text { Aerial Photograph } \\
\text { ii. } & \text { Airborne LiDAR }\end{array}$ \\
\hline ii. & $\begin{array}{l}\text { SOP disaster } \\
\text { management from } \\
\text { website }\end{array}$ & $\begin{array}{l}\text { iii. Existing landslide } \\
\text { inventory }\end{array}$ \\
\hline iii. & $\begin{array}{l}\text { Non-structural } \\
\text { mitigation } \\
\text { activities }\end{array}$ & \\
\hline
\end{tabular}

Table 1. Data gathering and compilation

\subsubsection{Primary Data}

Primary data for this study is data of non-structural mitigation in disaster management metamodel. This data are obtained from website by identifying the activities involved in non-structural mitigation of disaster management to record in the metamodel. Any information about mitigation phase in disaster management that find in the website is acceptable. This information is important in order to deliver the information in the effective way using geospatial metamodel.

\subsubsection{Secondary Data}

The secondary data for this study are Digital Terrain Model (DTM) and orthophoto of Kundasang, Sabah acquired from service provider which is Department of Mineral and Geoscience Malaysia (JMG). The DTM data was given in raster dataset format (.tiff) and the data has $0.25 \mathrm{~m}$ spatial resolution. The orthophoto data was given in ECW file with $0.07 \mathrm{~m}$ spatial resolution for each separated area. In addition, existing landslide inventory mapping for Kundasang area was supplied by JMG to compare with the landslide inventory mapping that was to be created. Existing data was given in shape file format with information about the landslide inventory such as type, activity and features of the landslide.

\subsection{Development of Geospatial Metamodel}

Geospatial metamodel for disaster management is developed to help provide user with information about landslide. For doing this, the study area of landslide is in Kundasang, Sabah, which has the significant number of landslide is put in place. To design this geospatial metamodel, Microsoft Access is appropriate tool because this software is user friendly.

To store the information, information must be collected by searching any related landslide or disaster study that incorporates metamodel before designing the metamodel. The information will be recorded in the table on the Microsoft Access before the form is created. Examples of information that will be recorded are name of activity and the tasks that are carried out. Figure 4 shows an example of geospatial metamodel for preparedness phase in disaster management.

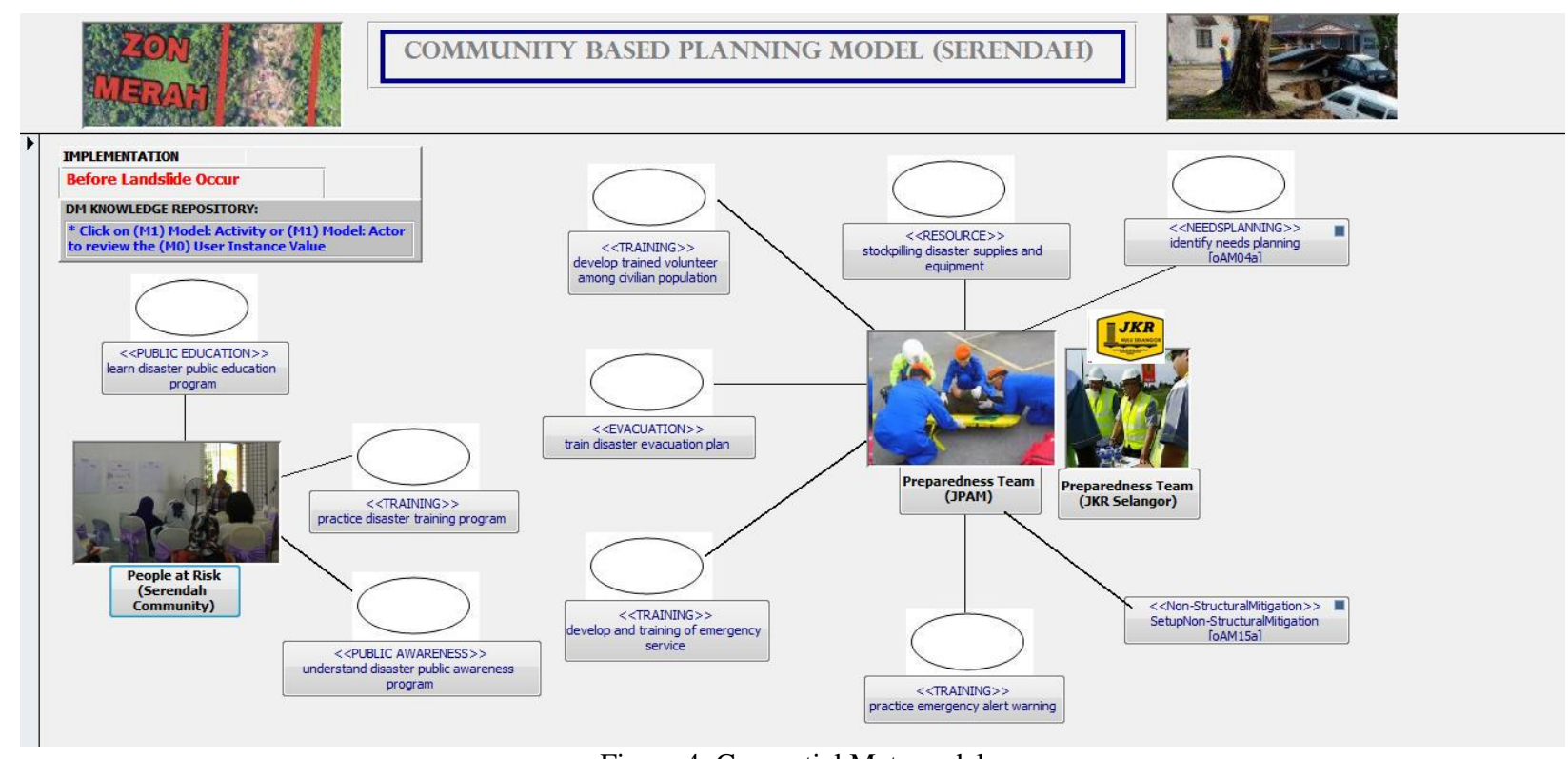

Figure 4. Geospatial Metamodel

\subsection{Landslide Inventory Mapping Data Pre-processing}

Data pre-processing is the important part to extract the information into appropriate form. An ideal procedure will provide a better result. The pre-processing consists of producing topographic openness, colour composite, hillshade and generation of landslide inventory map by using 0.25 meters Digital Terrain Model (DTM) of airborne LiDAR.
Based on digital terrain model (DTM), data such as topographic openness, colour composite and hillshade can be performed by using ILWIS, SAGA GIS and ArcGIS. After that, data that have been produced and orthophoto data will be inserted into ArcGIS to make sure image interpretation process can be carried out. 


\subsection{Generation of Landslide Inventory Mapping}

Generation of landslide inventory map needs information such as ID, types of landslide, activity of landslide and feature of landslide. This map can produce final hard copy map that shows the landslide in Kundasang, Sabah with the information about the landslide. Data that have been produced will be used for image interpretation in order to generate landslide inventory.

Image interpretation can be defined as the study of the imaged objects of the earth surface, the extraction of those features relevant to the object of study, the analysis of the selected features with the objective to come to a deduction of their significance for the specific field of study (Soeters and Van Westen, 1996). The data will overlay together and it can be used to identify and digitize the landslide inventory. The information contained in the landslide inventory map are ID landslide, type of landslide, activity of landslide and feature of landslide.

\section{RESULT AND ANALYSIS}

There are three main sections. The first section will discuss the geospatial metamodel, which is show the information about non-structural mitigation of landslide. The second section shows data pre-processing procedure, which is used to produce data to enable better visualization in order to generate landslide inventory. The final section shows the result and analysis from the processing stage, which consists of landslide inventory map that will put in the geospatial metamodel.

\subsection{Development of Geospatial Metamodel}

Geospatial metamodel for non-structural mitigation of disaster management (GeoMet) is produced as a prototype system to deliver information to the user about the landslide effect and as a platform to show landslide inventory map. The information will be stored in the table before the form is created. The table will link using unique value of activity ID to make sure the data is shown in the correct form. Figure 5 shows the table and form of geospatial metamodel with the information about the landslide inventory and task of activity.

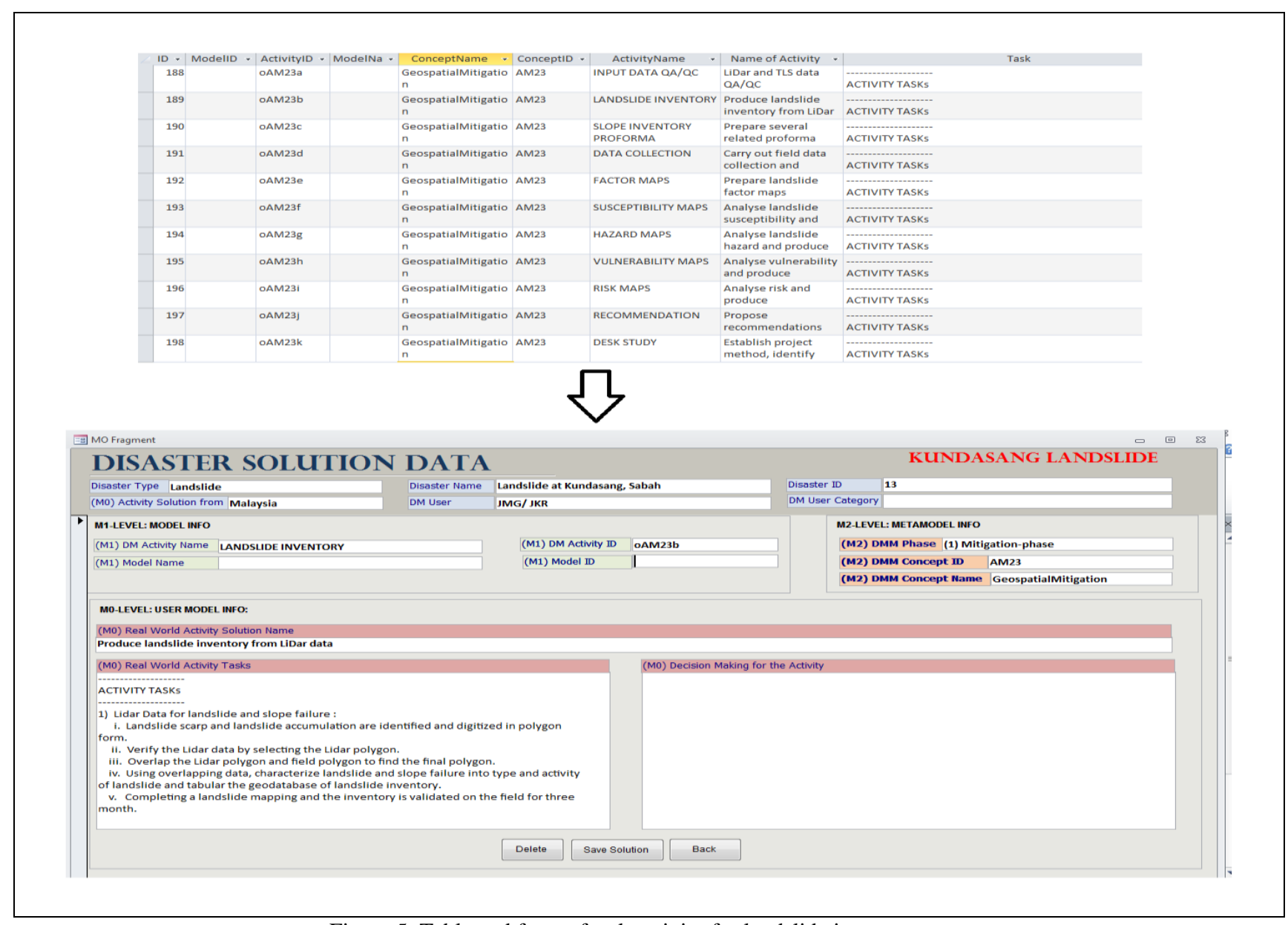

Figure 5. Table and form of task activity for landslide inventory map

In addition, to make sure the flow of non-structural mitigation can be represented easily, the flowchart of work for nonstructural mitigation has been created. This flowchart is the procedure of non-structural mitigation of landslide, which is step-by-step procedure from beginning until the final hazard mapping is achieved. This flow also must ensure that each procedure of non-structural mitigation can be implemented correctly. Figure 6 shows the flow diagram of non-structural mitigation in GeoMet. 


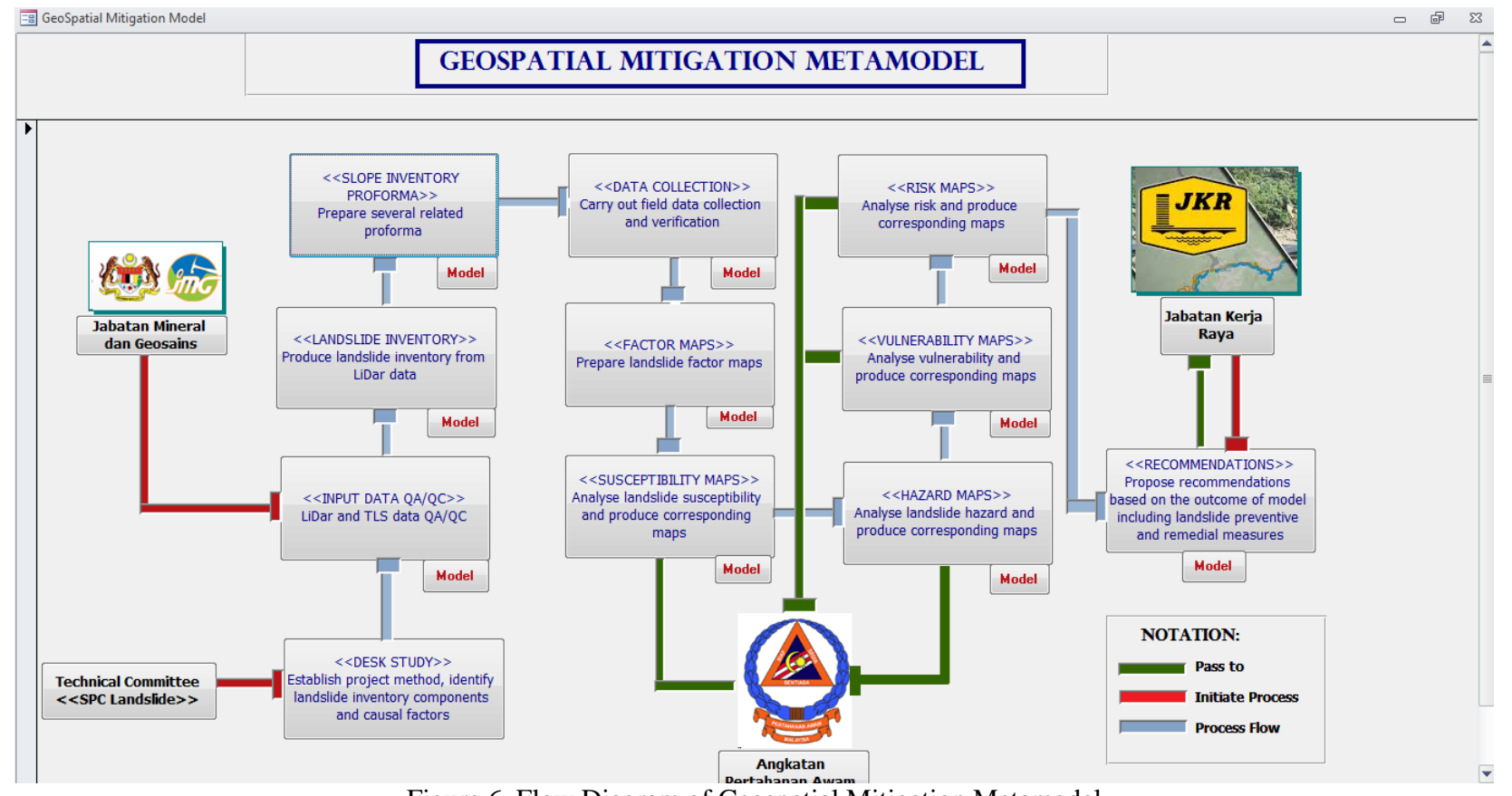

Figure 6. Flow Diagram of Geospatial Mitigation Metamodel

Each procedure of non-structural mitigation will have the work flow model that describes the information about the procedure of each work. This model is created to make sure users can easily understand each procedure and can make effective decisions. Figure 7 shows the example of model in landslide inventory. The landslide inventory map button in the landslide inventory model is the map of each landslide inventory, which are activity, type, feature and combination of type and activity of landslide.

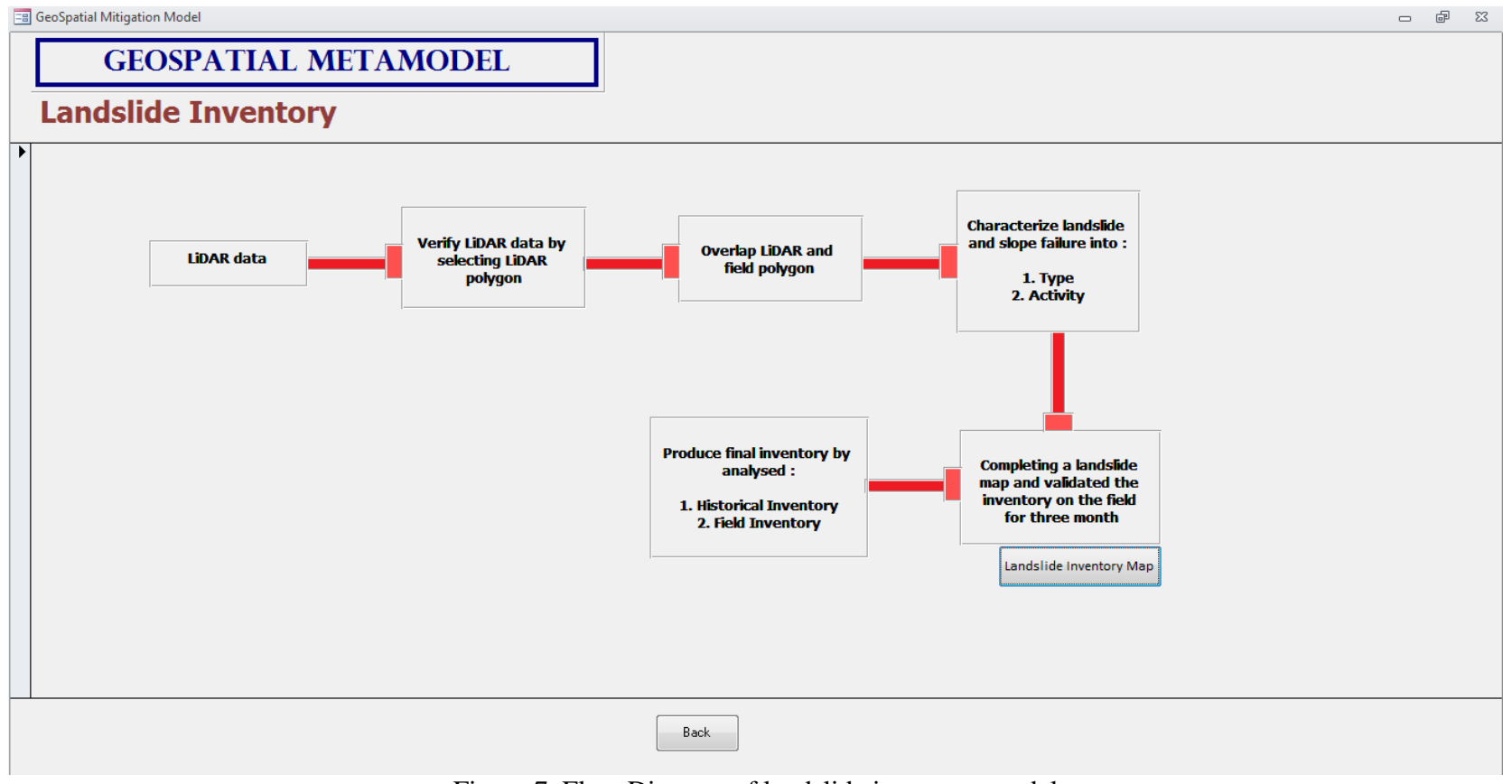

Figure 7. Flow Diagram of landslide inventory model

The landslide inventory map will also be imported into the geospatial metamodel that shows information about the location of the landslide, type of landslide, activity of landslide and feature of landslide. There are four interfaces that show information of each landslide inventory map. Figure 8 shows the first interface of landslide inventory map shown in the geospatial metamodel. 


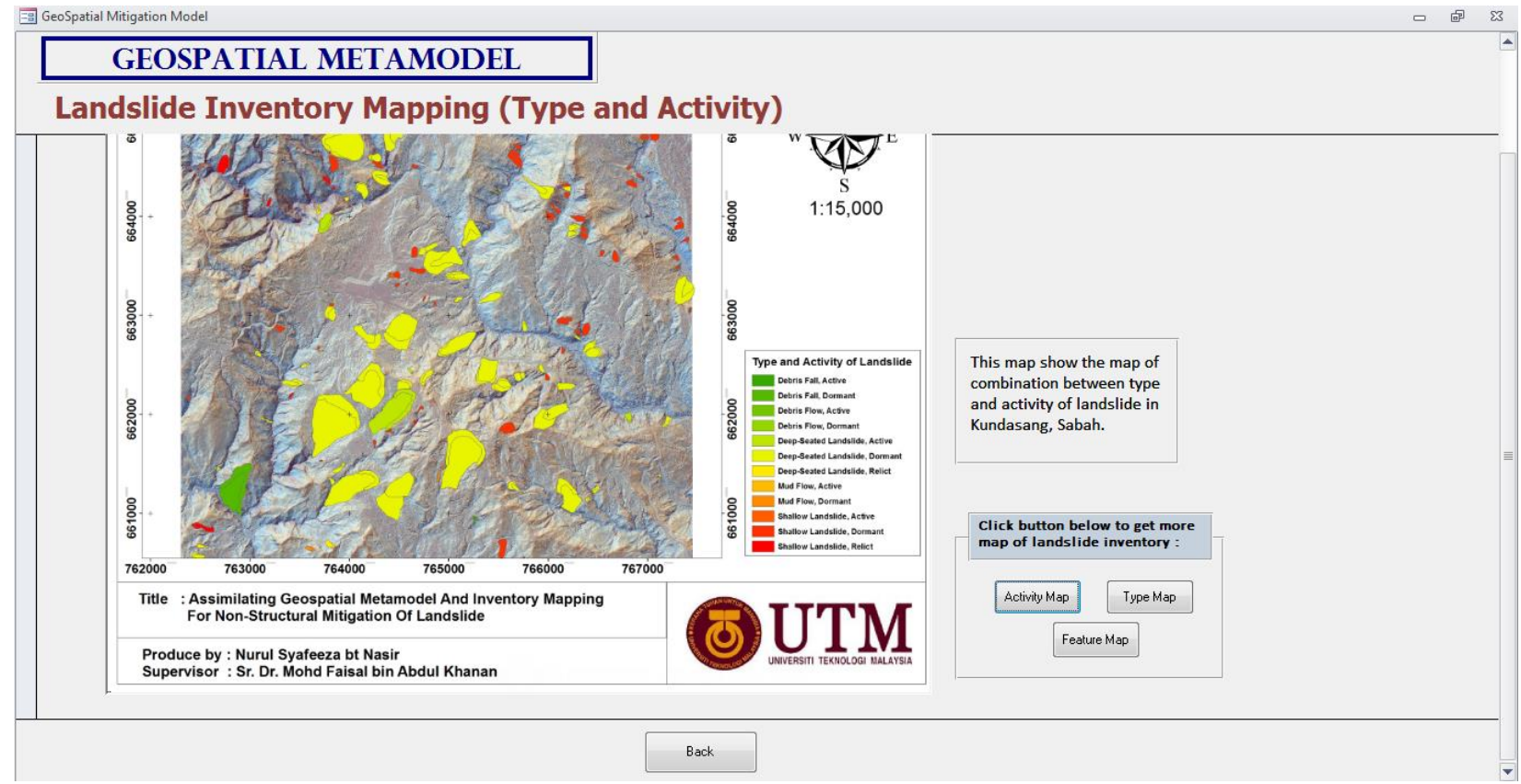

Figure 8. Landslide Inventory Map in GeoMet

The second interface shows the information about activity of landslide inventory. In this interface, there be have information about map of activity, description about activity of landslide which are active, dormant and relict. Figure 9 shows the activity of landslide inventory map in GeoMet.

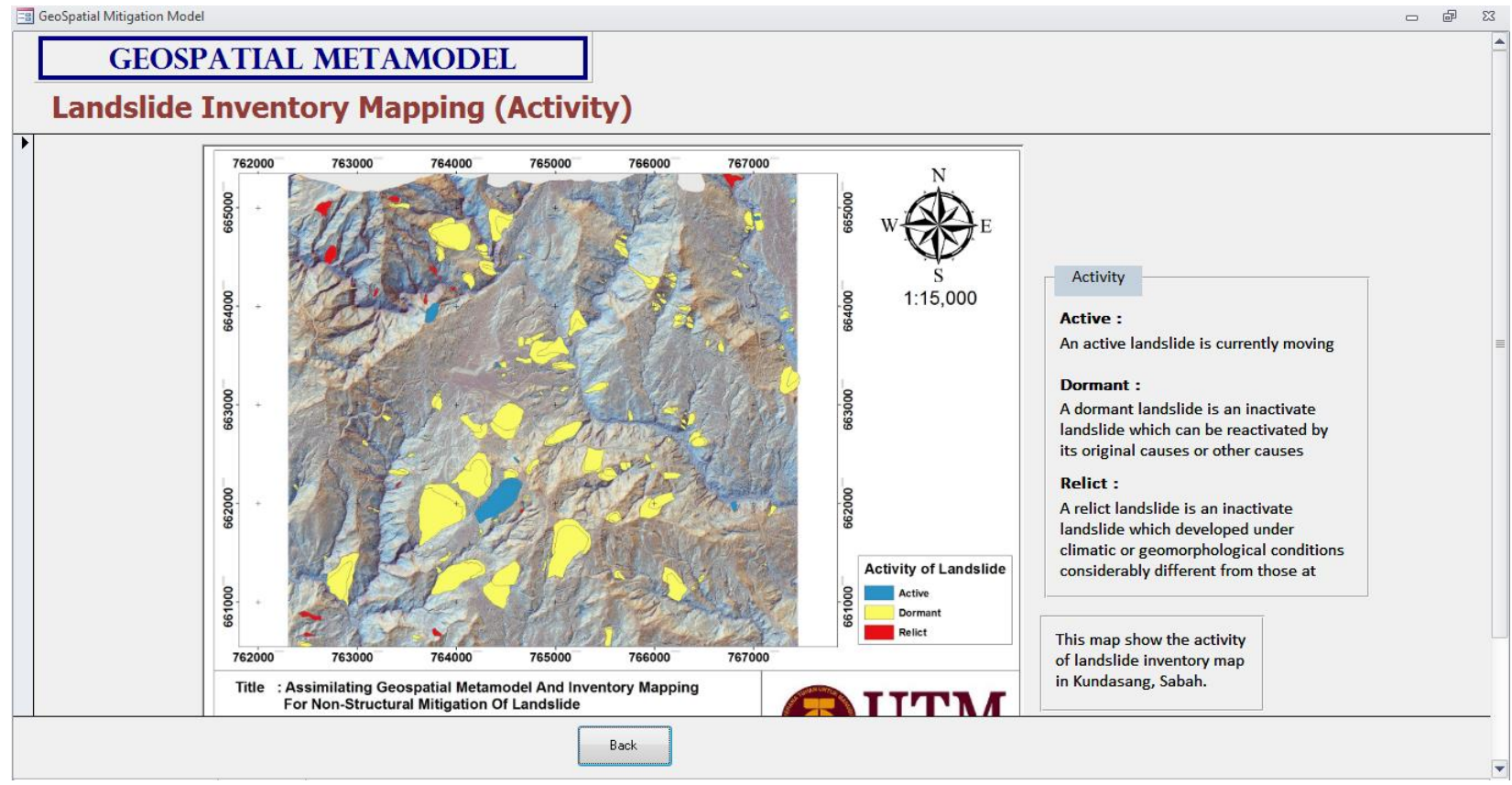

Figure 9. Activity of Landslide Inventory Map in GeoMet

The third interface of geospatial metamodel is the type of landslide inventory as shown in Figure 10. There are five types of landslide in Kundasang, Sabah, which are debris fall, debris flow, mud flow, deep-seated landslide and shallow landslide.
The descriptions about each landslide have been shown in the GeoMet to make sure users can get the information about the type of landslide easily. 


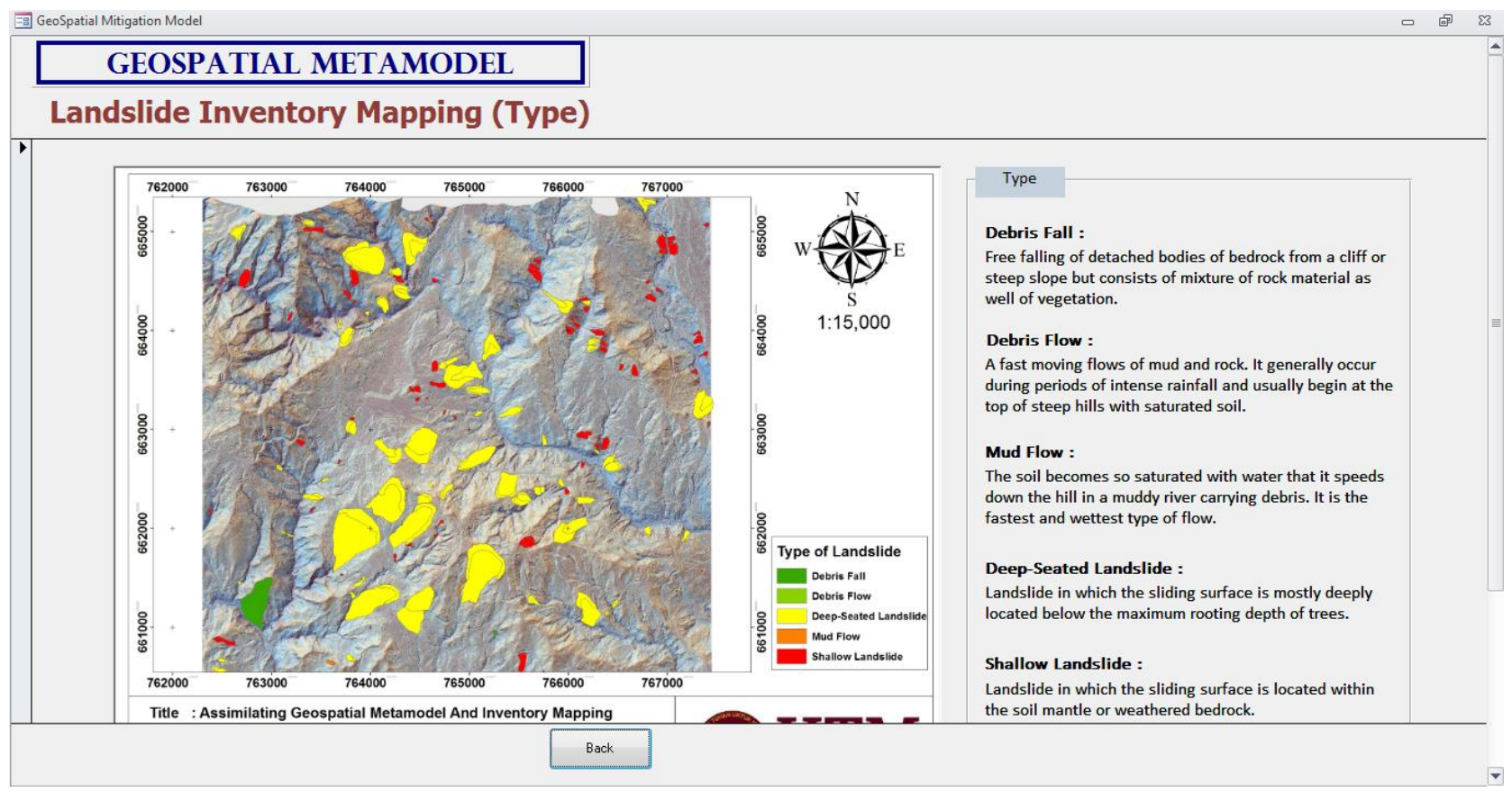

Figure 10. Type of Landslide Inventory Map in GeoMet

The final interface of Geospatial Metamodel is feature of landslide. Figure 11 shows the feature of landslide inventory map in GeoMet. Description about definition of accumulation area and scarp area is also featured in GeoMet in order to make sure the information can be delivering effectively.

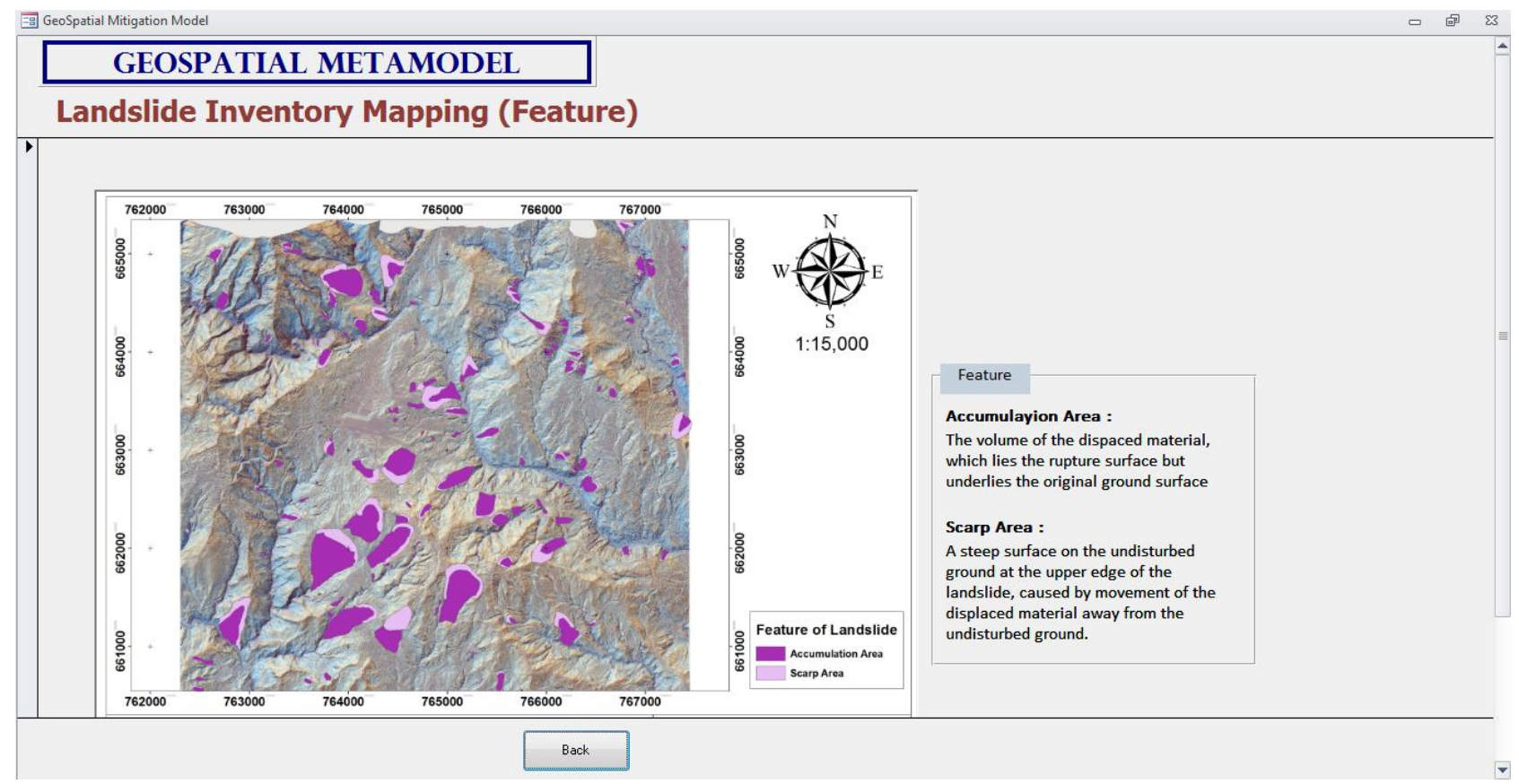

Figure 11. Feature of Landslide Inventory Map in GeoMet

\subsection{Landslide Inventory Mapping Data Pre-processing}

The populated maps of landslide inventory are in actual processed much earlier. The data pre-processing procedure involves processing digital terrain model (DTM) to produce topographic openness, colour composite, and hillshade images. The purpose of producing these images is to make a better visualisation in order to identify landslide inventory that occur in Kundasang, Sabah. The images were produced by using 0.25 meters digital terrain model (DTM) of airborne LiDAR. The images will be overlaid in the ArcGIS software to make sure the next step can be carried out, which is to identify the landslide inventory in Kundasang.

Topographic openness is an angular measure of the relation between surface relief and horizontal distance (R. Yokoyama et. al., 2002) Openness has two viewer perspectives, which are positive and negative. Figure 12 shows the result of positive topographic openness image produced by using SAGA GIS. This is called positive topographic openness due to the positive values that express openness above the surface and make it easy to recognize the openness texture such as steep ridge. 


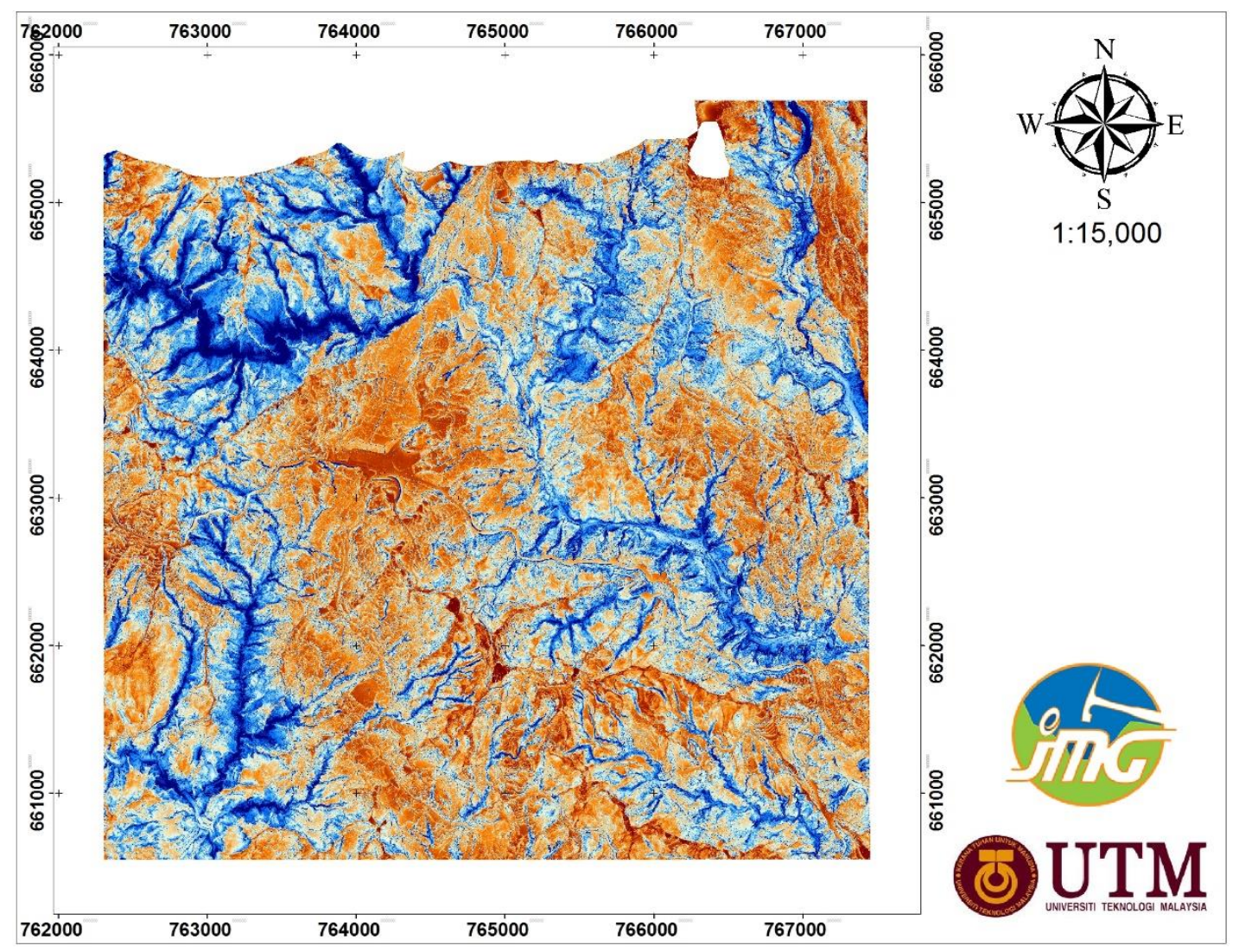

Figure 12. Positive Topographic Openness

Figure 13 shows the negative topographic openness image. below the surface. Negative openness has been related to how Negative topographic openness image describes the information wide a landscape can be viewed from any position.

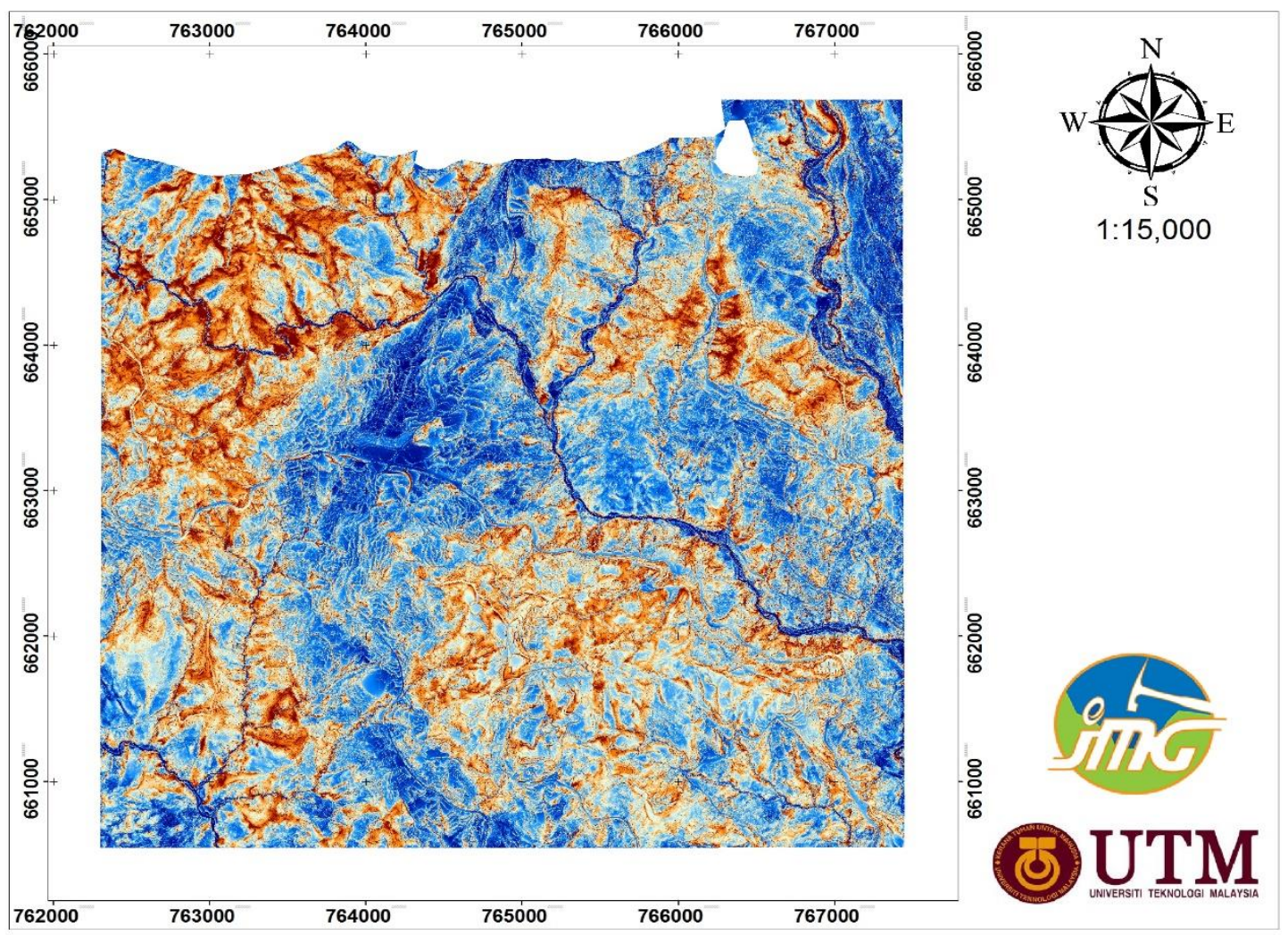

Figure 13. Negative Topographic Openness 
Colour composite gives a visual impression of raster bands and puts the bands together in one colour composite image. Figure 14 shows the colour composite image in Kundasang, Sabah by using ILWIS software. This image gives a better visual impression of the relief in Kundasang area. For image interpretation purposes, a colour composite may be useful as a background image during on-screen digitizing.

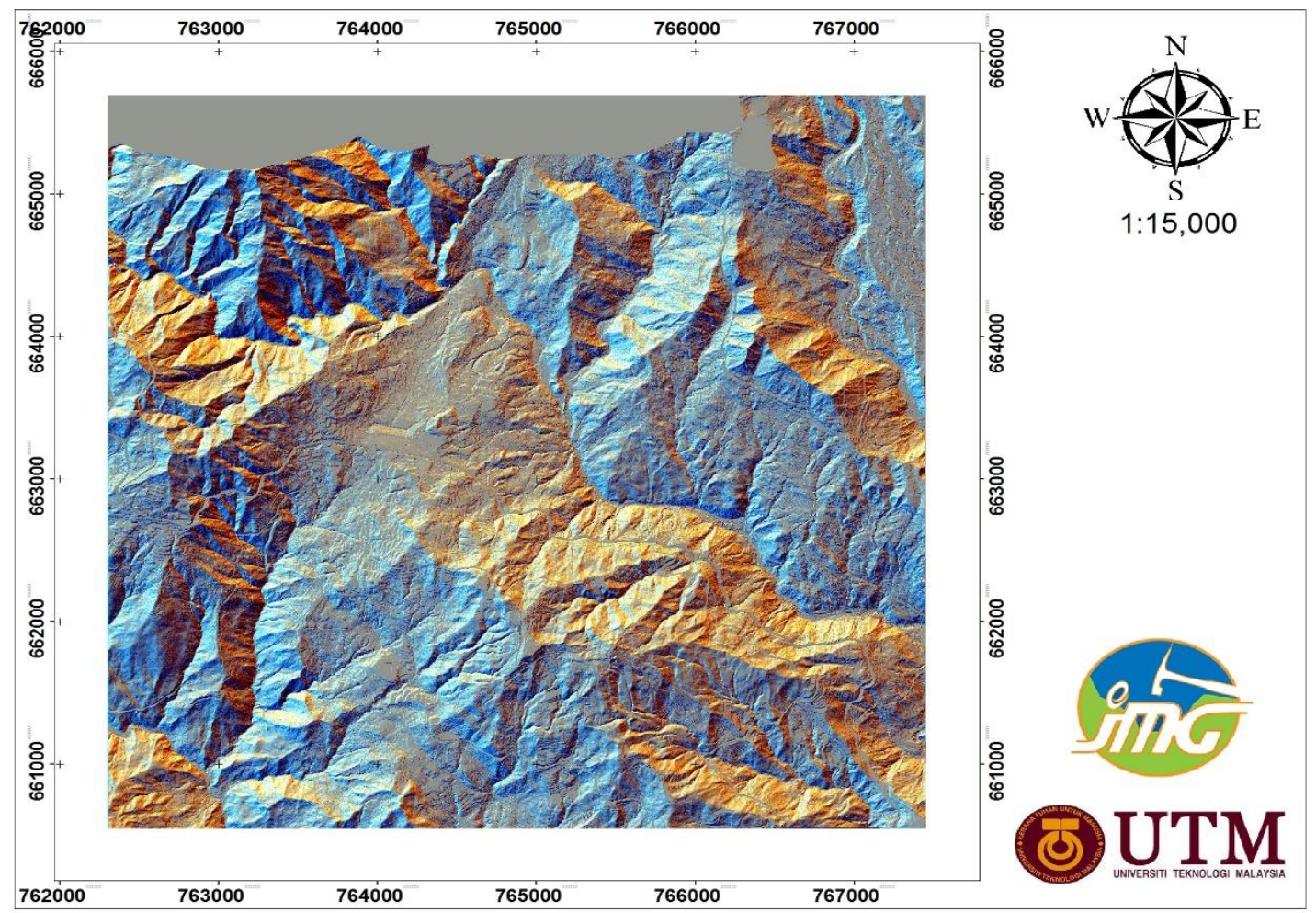

Figure 14. Colour Composite

In addition, hillshade image is a greyscale that represents the surface with the shading image. Figure 15 shows the hillshade image of Kundasang, Sabah by using ArcGIS. Greyscale colour ramp is used to display a hillshade elevation mode of the terrain surface. Hillshade is a technique for visualizing terrain, slope and aspect of the elevation surface.

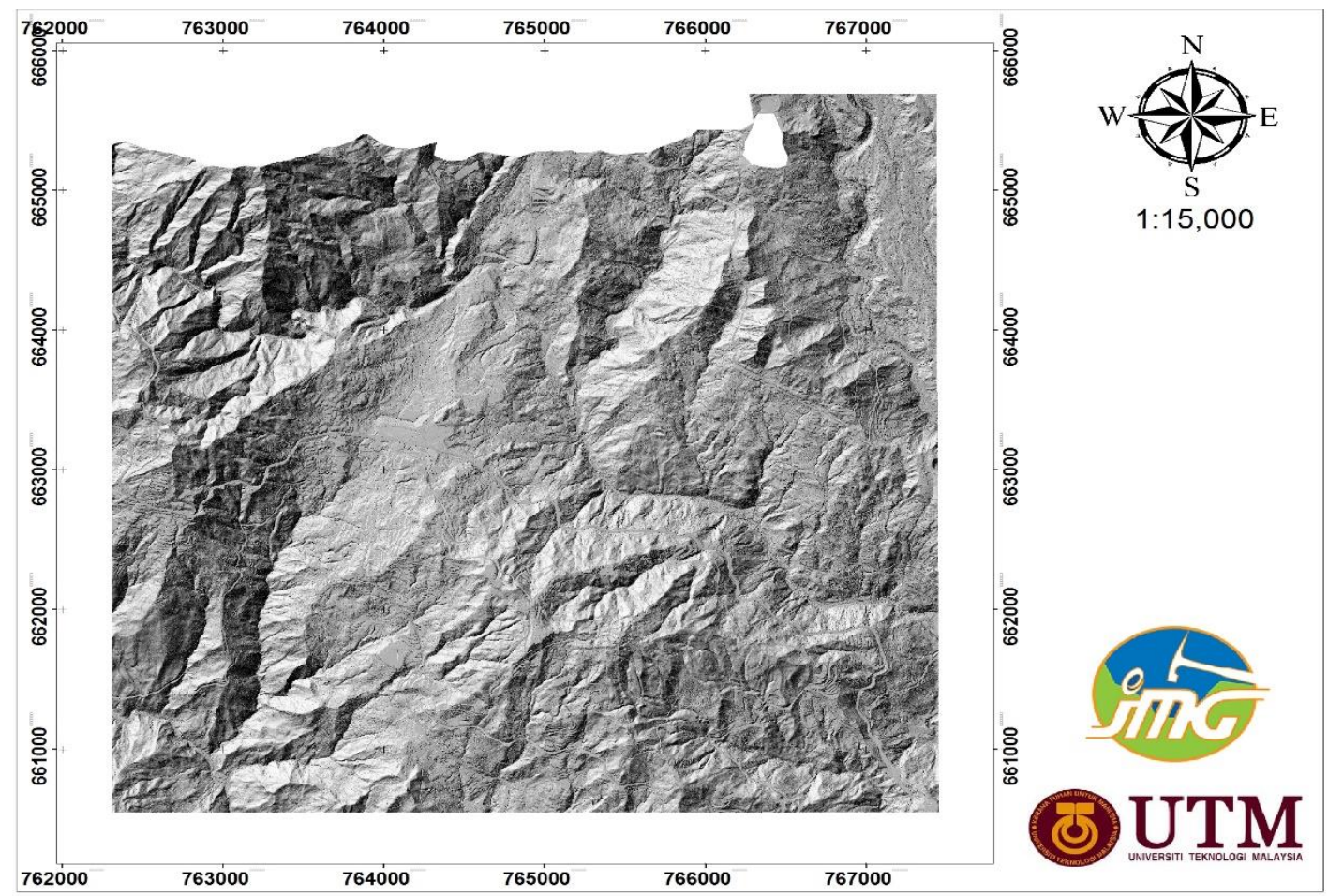

Figure 15. Hillshade 


\subsection{Generation of Landslide Inventory Mapping}

According to Van Westen et al., (2008), landslide inventories are the basis for landslide susceptibility, hazard and risk. In this study, the topographic openness, colour composite, hillshade and orthophoto images with $0.07 \mathrm{~m}$ spatial resolution are carried out to make sure the process of identifying landslide inventory can be performed. Figure 16 shows the image interpretation of this study area.

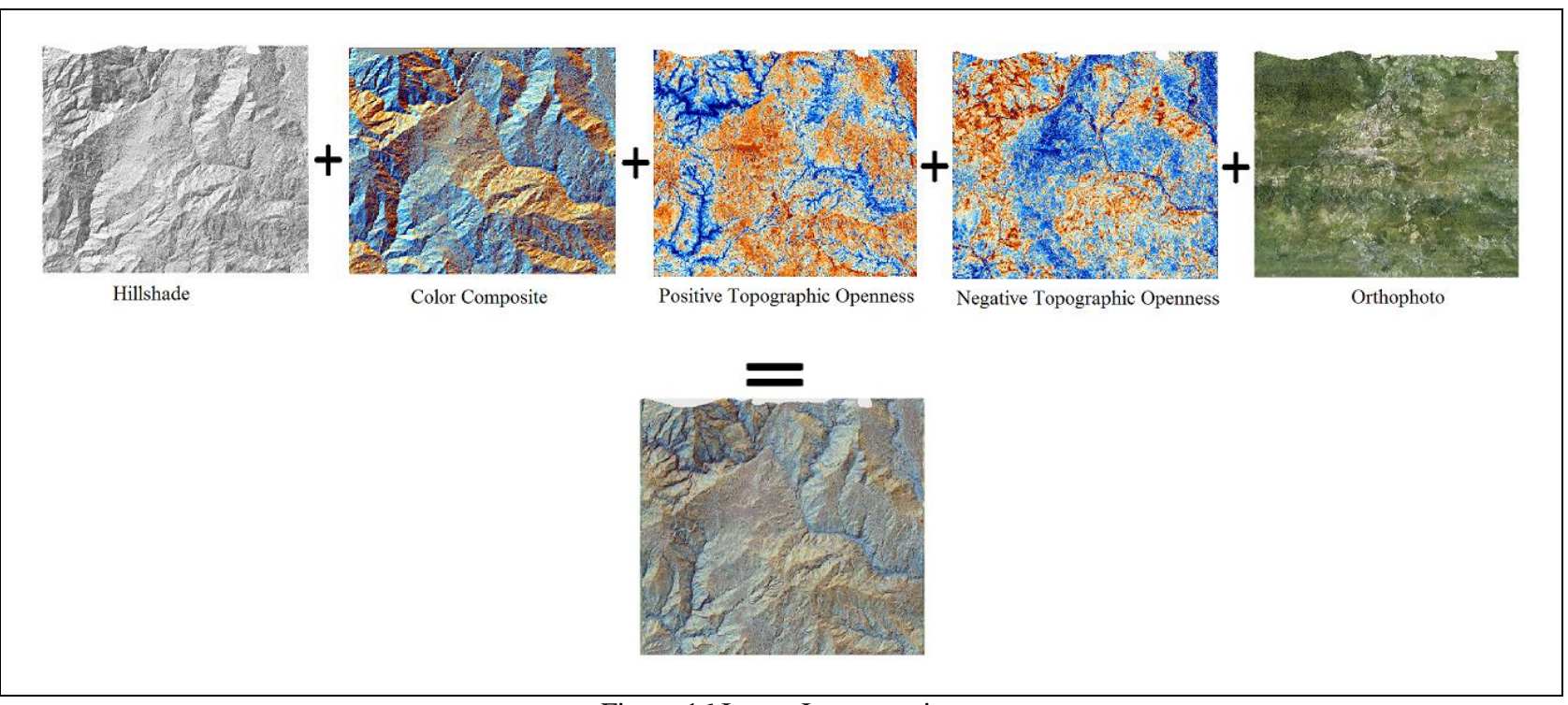

Figure 16 Image Interpretation

In this study, four landslide inventory maps are produced, which are, type of landslide inventory map, activity of landslide inventory map, feature of landslide inventory map and combination of all information of landslide inventory map. The landslide inventory map as shown in Figure 17. The area of this study is $26,454,100.1432$ meter square and five types and three activities of landslide that occur in Kundasang, Sabah have been identified.

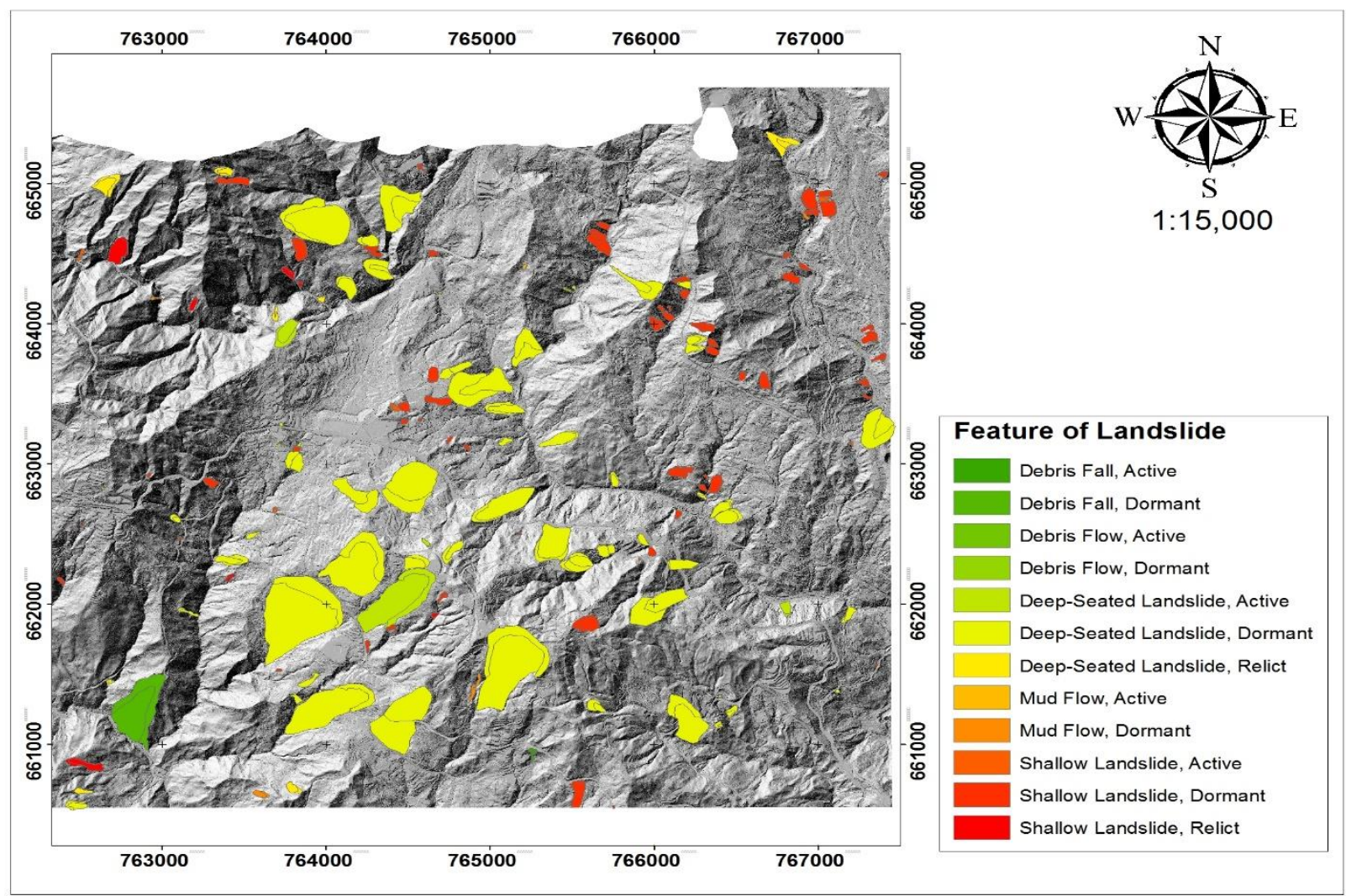

Figure 17. Landslide Inventory Map

The landslide types include mud flow (8 landslide), debris fall (2 landslide), debris flow (2 landslide), deep-seated landslide
(77 landslide) and shallow landslide (90 landslide) while the total activities of landslide are active (21 landslide), dormant 
(144 landslide) and relict (14 landslide). The statistics of type and activity of landslide are shown in table 2 and table 3 .

\begin{tabular}{|c|c|}
\hline Type & Percentage (\%) \\
\hline Mud Flow & 4.47 \\
\hline Debris Fall & 1.12 \\
\hline Debris Flow & 1.12 \\
\hline Deep-seated Landslide & 43.01 \\
\hline Shallow Landslide & 50.28 \\
\hline
\end{tabular}

Table 2. Statistics of landslide type

\begin{tabular}{|c|c|}
\hline Type & Percentage (\%) \\
\hline Active & 11.73 \\
\hline Dormant & 80.45 \\
\hline Relict & 7.82 \\
\hline
\end{tabular}

Table 3. Statistics of landslide activity

\subsubsection{Analysis of Landslide Inventory Map with the} Existing Landslide Inventory Map

Existing landslide inventory map is used to make an analysis and find the similarity percentage between the existing landslide inventory that has been produced by JMG and the new landslide inventory. By using tabular intersection method in ArcGIS software, the area and percentage of landslide inventory that intersect can be calculated and identified. The result of this method shows the similarity between the existing and new landslide inventory map is $83 \%$. Table 4 shows the similarity percentage landslide inventory that intersects between the features.

\begin{tabular}{|c|c|c|c|}
\hline $\begin{array}{l}\text { Type of } \\
\text { Landslide }\end{array}$ & Area & $\begin{array}{c}\text { Percentage } \\
(\%)\end{array}$ & $\begin{array}{c}\text { Similari } \\
\text { ty }(\%)\end{array}$ \\
\hline $\begin{array}{l}\text { Debris Fall - } \\
\text { Debris Fall }\end{array}$ & 94572.064 & $100 \%$ & \\
\hline $\begin{array}{l}\text { Mud Flow - } \\
\text { Mud Flow }\end{array}$ & 10896.247 & $100 \%$ & \\
\hline $\begin{array}{l}\text { Debris Flow - } \\
\text { Debris Flow }\end{array}$ & 484.642 & $36 \%$ & \\
\hline $\begin{array}{l}\text { Deep-Seated } \\
\text { Landslide - } \\
\text { Deep-Seated } \\
\text { Landslide }\end{array}$ & 1622369.052 & $93 \%$ & $83 \%$ \\
\hline $\begin{array}{l}\text { Shallow } \\
\text { Landslide - } \\
\text { Shallow } \\
\text { Landslide }\end{array}$ & 229685.014 & $86 \%$ & \\
\hline
\end{tabular}

Table 4. Similarity of intersect landslide inventory

Comparison between two maps of landslide inventory show error will still occur which include digitizing errors and other mistakes introduced in the construction of digital cartographic database (Carrara et al., 1992). In the Galli et al. (2008) research, the detailed geomorphological inventory shows $44.6 \%$ of the total number of landslides shown in multi-temporal inventory. Galli et al. research, shows the similarity between two maps were $44.6 \%$ and the results are different if the area of the mapped landslides is considered.

\section{CONCLUSION}

Information of landslide inventory map in geospatial metamodel is needed for local agency (NADMA) and local authority to prepare for any upcoming landslide events. Landslide inventory map provide benefits such as providing the current landslide with reliable information about type of landslide, activity of landslide and feature of landslide. This study was conducted in Kundasang, Sabah based on the occurrence of consecutive landslide events in 2014. Main aim of this study is to produce metamodel and map for mitigation phase in disaster management by applying geospatial aspects was achieved when Geospatial Metamodel (GeoMet) and landslide inventory mapping are produced.

Geospatial metamodel and landslide inventory map are practicable tools to prepare and mitigate landslide hazard impact. This method is more efficient to produce geospatial information about disaster management using metamodel system compared to the hard engineering approach. In addition, the result of combination of Geographic Information System (GIS), Remote Sensing and technology can be used in study wide area to assist the responsible agencies of hazard occurrence and to provide information about landslide.

Landslide inventory map that has been produced shows Kundasang, Sabah has 179 landslides, of which as many as 21 landslides are active. Therefore, precautionary measures should be taken to ensure that undesired events can be mitigated and one of the effective tools is GeoMet.

However, there is still much work to do regarding the geospatial metamodel and landslide inventory map, such as limited information of landslide in order to provide the information to the public and agencies involved. GeoMet can be improved by adding more information in the landslide inventory map such as movement of landslide. GeoMet can also be improved by producing more landslide map such as landslide susceptibility map and landslide vulnerability map to put in the metamodel.

\section{ACKNOWLEDGEMENTS}

The authors are grateful to Minerals and Geoscience Department Malaysia (JMG) for providing LiDAR, orthophoto and existing landslide inventory data, respectively. This study is funded by Universiti Teknologi Malaysia, Vote Number Q.J130000.2627.13J88. Special thanks also to Universiti Teknologi Malaysia for providing the financial support to attend the GGT2018.

\section{REFERENCES}

Agliardi, F. (2012). Landslides: definitions, classification, causes.

Chatterjee, S. (2016). Disaster Management definition, process, various phases and key components of preparedness. 
Danish K., Sadaf Q., I. S. H. Harahap, Syed B. (2017). Landside of Highland Towers 1993 : a case study of Malaysia.

The Star Online (2015). Things go sour for starberry farm. Retrived from https://www.thestar.com.my/news/nation/2015/06/26/things-gosour-for-strawberry-farm-earthquaketriggered-landslide-bringssuccessful-business-crashing/

Visconti, M., \& Cook, C. R. (2002, December). A meta-model framework for software process modeling. In International Conference on Product Focused Software Process Improvement (pp. 532-545). Springer, Berlin, Heidelberg.

Berci, M., Toporov, V. V., Hewson, R. W., and Gaskell, P. H. (2009). Metamodelling Based on High and Low Fidelity Models Interaction for UAV Gust Performance Optimization. UK: University of Leeds.

Othman, S. H., \& Beydoun, G. (2010). A Disaster Management Metamodel (DMM) Validated. In Knowledge Management and Acquisition for Smart Systems and Services (pp. 111-125).

Petley, D. (2015). Landslide-induced sediment production after the Sabah earthquake in Malaysia.

New Straits Time (2017). Landslide at the foothill of Mount Kinabalu expected; aftter effects of 2015 earthquake. Retrieved from https://www.nst.com.my/news/nation/2017/10/293517/landslide -foothill-mount-kinabalu-expected-after-effects-2015earthquake

Soeters, R., Van Westen, C.J., (1996). Slope instability recognition, analysis and zonation. In: Turner, A.K., Schuster, R.L. (eds). Landslides, Investigation and Mitigation. Transportation Research Board, National Research Council, Special Report 247, National Academy Press, Washington D.C., U.S.A., pp. 129-177.

R. Yokoyama, M. Shirasawa, Richard J. Pike (2002). Visualizing Topography by Openness: A New Application of Image Processing to Digital Elevation Models.

Van Westen, C. J., Castellanos, E., \& Kuriakose, S. L. (2008). Spatial data for landslide susceptibility, hazard, and vulnerability assessment: an overview. Engineering geology, 102(3), 112-131.

Alberto Carrara, Mauro Cardinali, Fausto Guzzetti, Paola Reichenbach (1992). DOI : 10.1007/978-94-015-8404-3_8

Mirco Galli, Francesca Ardizzone, Mauro Cardinali, Fausto Guzzetti, Paola Reichenbach (2008). Comparing landslide inventory

https://doi.org/10.1016/j.geomorph.2006.09.023

maps. 